\title{
Expressed Needs of Students for Prevention of Internet Addiction: A Content Analysis Study
}

\author{
Babak Nemat Shahrbabaki, ${ }^{1}$ Arezoo Fallahi, ${ }^{2,}$ and Piraveen Pirakalathanan ${ }^{3}$ \\ ${ }^{1}$ Ms Health Service Management, Health Network of Sanandaj, Kurdistan University of Medical Sciences, Sanandaj, Iran \\ ${ }^{2}$ Assistant Professor, Department of Public Health, Faculty of Health, Kurdistan University of Medical Sciences, Sanandaj, Iran \\ ${ }^{3}$ Chief Medical Officer, Sonoa Health, Melbourne, Australia \\ "Corresponding author: Arezoo Fallahi, Department of Public Health, Faculty of Health, Kurdistan University of Medical Sciences, Pasdaran Boulevard, P.O. Box 66177-13446, \\ Sanandaj, Iran. Tel: +98-8731827507, Fax: +98-8733625131, E-mail: arezofalahi91@gmail.com
}

Received 2016 July 17; Revised 2016 November 14; Accepted 2016 December 06.

\begin{abstract}
Background: College students are particularly vulnerable to developing Internet addiction. Understanding students' needs for preventing as well as managing Internet addiction should be considered.

Objectives: The purpose of this study was to explore the multidimensional needs of students for the prevention of Internet addiction.

Methods: This qualitative study was performed in Sanandaj, Iran, between September and December 2015. Fifteen participants who are addicted to the Internet, based upon a self-reported questionnaire, were purposefully selected from 3 local universities. Data was collected using focus groups, individual semi-structured interviews, and drawings. Conventional content analysis methods were utilized to analyze data.

Results: Fifteen students (mean age $26.3 \pm 3.2$ years) with an average score for Internet addiction of 59.3 participated in the study. Students' needs for the prevention of Internet addiction included 4 major categories: social support, personal competence, appropriate culture, as well as maintenance and improvement of health.

Conclusions: Prevention programs for Internet addiction need to promote social supports, teach personal competence, establish an appropriate culture, and prioritize good health.
\end{abstract}

Keywords: Internet, Addiction, Students, Qualitative Research

\section{Background}

Internet usage has exponentially grown over the last decade $(1,2)$ and is changing people's lives all over the world (1). The major features of the Internet, such as availability, interactivity, and extent of information, make it attractive, especially for college students (3). Internet addiction (IA), compulsive Internet use, is one of the individual and social problems of Internet overusing (4). Based on the findings of researchers, IA has become a global problem (5, $6)$.

Studies stated that students seem greatly susceptible to IA than other groups (7-9). More than $30 \%$ of college students have demonstrated IA signs, such as spending significant amount of time online, compulsive behavior, and time-management problems (10). IA for Taiwanese students, Italian students, and Chinese students is $12.3 \%$, $36.7 \%$, and $9.8 \%$, respectively (11). According to recent statistics, $60 \%$ of Iranian people use the Internet and $40 \%$ are between the ages of 20 and 29 years (12). Internet usage is growing very rapidly among Iranian students (3) and prevalence of Internet addiction among them is $43.7 \%$ (13). Some determinants of IA are including: sex, unemploy- ment, living in metropolitan areas, and parental literacy $(3,14)$. Furthermore, cultural, social, psychological, and genetic factors have been found to be effective on IA $(15,16)$.

In Iran, most students live in school dormitories where they have free and ready access to the Internet. They discover new interactions with the world through the Internet and find the Internet to be a convenient choice for promoting themselves and communicating with others (17). However, Iranian students are worried about the pathological use of the Internet (3), which results in personal, family, academic, financial, and occupational problems (18). The problem of IA has become a mainstream subject for researchers, psychiatrists, and educators and it is currently becoming a critical mental health disorder among Iranian students (19).

\section{Objectives}

In Iran, studies have investigated the prevalence of IA, associated factors, and its effects among students based on quantitative research $(10,17)$, however, they have not surveyed students' needs for the prevention of IA based on 
qualitative research. Qualitative research seeks to understand a given research problem and can produce a rich and deep description from the individual's perspective (20).

Understanding students' needs through in-depth interviews can be useful to design strategies for the prevention and/or management of IA (1). This study aims to explore the expressed needs of students for prevention of IA based-on qaulitative research.

\section{Methods}

This qualitative study, conventional content analysis approach, was performed in Sanandaj, Iran, between September and December 2015. Overcoming shortcomings of quantitative researches and limitation of literature in exploring students' needs for the prevention of Internet addiction were reasons for use of this approach. Participants with IA were purposefully sampled from 3 local universities (Kurdistan University of Medical Sciences, Kurdistan University and Islamic Azad University) in Sanandaj, Iran. The inclusion criteria for this study comprised of students with IA and tendency to participate in the study. The exclusion criterion, however, included students with other addictions (drugs, alcohol, cigarettes...). Young's questionnaire was used to identify participants with IA(a score of 20 or more) (16). A total of 300 students completed the questionnaire; 20 students were identified to have IA. A total of 15 students aged between 20 and 33 years consented to participate in the study. In a statement of open disclosure, a nominal payment $(200,000$ Rial) was provided for participants to compensate for personal costs of time and travel.

Data was collected using focus groups (11), individual interviews (12), and drawings. Seven stages of the interview, including thematizing, designing, interviewing, transcribing, analyzing, verifying, and reporting were taken into consideration (21). An interview guide was designed to assist with the focus group and individual interviews. The guide focused upon questions relating to daily Internet utilization and perceived challenges associated with inability to access the Internet. Then, follow-up questions were asked according to the respondents' answers. At the end of each interview, notes were taken from each interview. Two focus groups with 4 participants per group and 7 individual interviews were conducted.

The first author in the study conducted interviews. He has the skills to perform the interview as well as manage them. Interviews were carried out in the consulting room, a quiet class or internet cafe at the university and the participants' home in different times of the day (in the morning and evening). The mean group and individual interview times were 55 and 31 minutes, respectively.
Drawing analysis has been shown to be a practical method for analyzing emotional states, with a potential to overcome barriers of vocal or short answer expression (3). Drawings have been used as a data collection method in research related to heart disease (22) and cancer (23) to identity patients' perspective of their illness. In this study participants were asked to formulate their ideas on prevention and management of IA. At the completion of the drawing, (15 drawings) students were asked to explain their thought processes.

Conventional content analysis method was utilized to analyze the interviews and interpretations of students' drawings (20). The steps of data analysis (manifest and latent content, unit of analysis, meaning unit, condensation, code, category, and theme) were as follows: transcribing interviews and interpretations of students' drawings and reading them several times, coding the participants' remarks, classify codes and comparing them based on their similarities and differences, providing sub categories and sub-themes, and finally describing the participants' views in each theme (20).

To ensure credibility and trustworthiness of the findings, 2 research team members analyzed the findings. Furthermore, findings were returned to the participants for members check. The reliability of the findings was ensured by early prescription, precise recording of the work procedures, mixed data collection methods, and mixed time as well as place $(24,25)$. NVivo version 9 was used to store, manage, and analyze the data.

Ethics approval was gained from Kurdistan University of Medical Science. All participants were asked to sign a consent form, which outlined confidentiality, publication prospectus, and their right to withdraw from the study.

\section{Results}

In total, 15 students aged 20 - 33 years old participated in the study. The average score for IA was 59.3. Most of the participants had 3 or more years of Internet usage. Participants' characteristics are shown in Table 1. Students' needs for the prevention of Internet addiction included 4 major categories: social support, personal competence, appropriate culture, as well as maintenance and improvement of health. Table 2 presents the categories, subcategories and remarks of the students regarding their needs for prevention of Internet addiction.

\subsection{Social Support}

Social support was described as critical to the prevention of IA in college students. This category has 3 
Table 1. Participants' Characteristics in the Study

\begin{tabular}{|c|c|}
\hline Variables & Value \\
\hline Age, $y$ & $26.3 \pm 3.2$ \\
\hline \multicolumn{2}{|l|}{ Sex } \\
\hline Male & 9 \\
\hline Female & 6 \\
\hline \multicolumn{2}{|l|}{ Number of children in family } \\
\hline 1 & 3 \\
\hline 2.4 & 7 \\
\hline $5-7$ & 5 \\
\hline \multicolumn{2}{|l|}{ Degree } \\
\hline Associate's degree & 3 \\
\hline Graduate degree & 9 \\
\hline Master's degree & 3 \\
\hline \multicolumn{2}{|l|}{ Father's occupation } \\
\hline Employee & 6 \\
\hline Non-employee & 9 \\
\hline \multicolumn{2}{|l|}{ Mather's occupation } \\
\hline Employee & 5 \\
\hline Housekeeper & 10 \\
\hline \multicolumn{2}{|l|}{ Father's literacy } \\
\hline Illiterate or elementary & 3 \\
\hline Diploma & 6 \\
\hline Associate's degree & 3 \\
\hline Master's degree & 3 \\
\hline \multicolumn{2}{|l|}{ Mother's literacy } \\
\hline Illiterate or elementary & 5 \\
\hline Diploma & 6 \\
\hline Associate's degree & 3 \\
\hline Master's degree & 1 \\
\hline \multicolumn{2}{|l|}{ Family's income } \\
\hline Good & 6 \\
\hline Average & 8 \\
\hline Poor & 1 \\
\hline Score of internet addiction & \\
\hline $20 \cdot 49$ & 2 \\
\hline $50-79$ & 7 \\
\hline $80-100$ & 6 \\
\hline \multicolumn{2}{|l|}{ Field of study } \\
\hline Medical and Health Sciences & 3 \\
\hline Technical Sciences & 8 \\
\hline Basic Sciences & 4 \\
\hline \multicolumn{2}{|l|}{ Residence } \\
\hline Dormitory & 8 \\
\hline Home & 7 \\
\hline
\end{tabular}

subcategories including family, university, and government/administration. Prevention programs for IA would need to address these subcategories.

One student stated that a close family structure and parental supervision were influential in preventing IA. She drew Figure 1 to illustrate her opinion. She remarked, "Families should know their children's needs. They should spend time with their children. Unfortunately, today's families aren't close and don't see each other very often" (26 year-old student). Other participants stated that the university environment fostered IA due to the high prevalence of Internet usage. One participant recommended, "holding sporting competitions and group activities in universities to lower Interne usage" (24 year-old student). Another participant mentioned, "unemployment is a major cause of Internet addiction" (29 year-old student). Governments and related administration have the capacity to reduce unemployment.

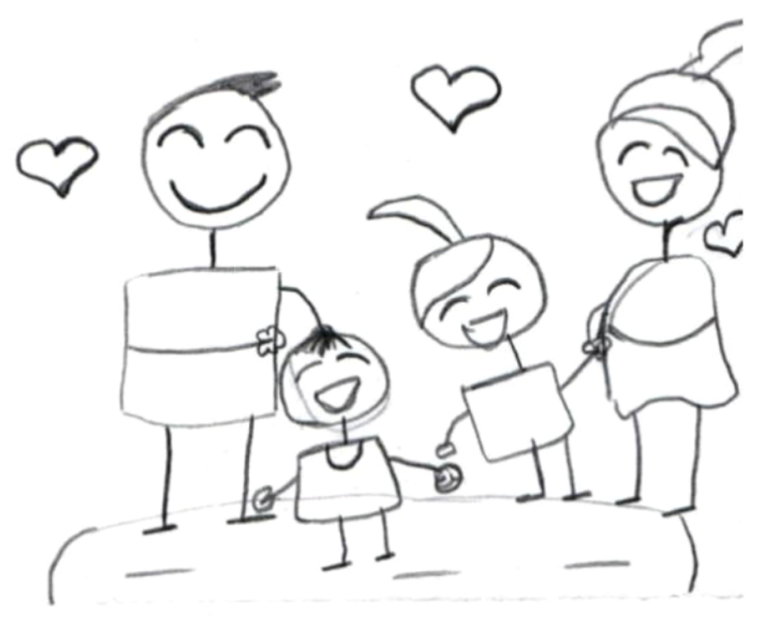

Figure 1. Social Support Needs of Participants to Reduce Internet Usage

\subsection{Personal Competence}

This category has 2 subcategories including selfefficacy and individual skills. Students in the study recognized the importance of being proactive in avoiding IA, by overcoming barriers, incremental goal setting, and self-reward. One student stated: "I feel I'm going crazy and can't control myself when internet is disconnected... I want to do everything; I want to keep norm behaviors" (A 23-year-old student).

Students identified the need for personal skills, such as self-awareness and regulation. One student drew Figure 2 and stated "I really want to do my work and university assignments, I need to feel self-satisfied and happy" (26 yearold student). However, a recurring issue was the lack of external support to assist with self-management. 
Table 2. Students' Needs for the Prevention of Internet Addiction

\begin{tabular}{|c|c|c|}
\hline Categories & Subcategories & Codes (Frequency) \\
\hline \multirow{3}{*}{ Social support } & Family & $\begin{array}{l}\text { Control children's use of the Internet (4), intimate members of the family (3), pay attention to } \\
\text { children's needs (8), managing children's plans (5), and engaging children in social activities } \\
\text { (9). }\end{array}$ \\
\hline & University & $\begin{array}{l}\text { Design entertainment programs for students (9), organize sports events (5), encourage } \\
\text { students to join research groups (9), establish time limits on Internet use (5). }\end{array}$ \\
\hline & Government or administration & $\begin{array}{l}\text { Create jobs for youth (13), create sports clubs and teams ( } 6 \text { ), collaborate with other } \\
\text { organizations to prevent Internet addiction ( } 4 \text { ), and create awareness by all government and } \\
\text { non-governmental agencies ( } 4 \text { ). }\end{array}$ \\
\hline \multirow{2}{*}{ Personal competence } & Self-efficacy & Overcome personal barriers (2), setting incremental goals (3), and self-reward (2). \\
\hline & Individual skills & $\begin{array}{l}\text { Encourage creativity (3), self-management }(1) \text {, self-awareness }(1) \text {, self-acceptance }(2) \text {, } \\
\text { self-regulation }(3) \text {, and self-motivation (1). }\end{array}$ \\
\hline \multirow{2}{*}{ Appropriate culture } & Education & $\begin{array}{l}\text { Life skills training (7), education about Internet usage (6), promote awareness about risks of } \\
\text { internet addiction ( } 7 \text { ), leverage media, scientific workshops and research programs (6), and } \\
\text { deliver education programs to primary school students about Internet usage (8). }\end{array}$ \\
\hline & Moral values & Respect to parents and elders (5), respect society values (2), and avoid anti-social behaviors (2). \\
\hline \multirow{2}{*}{ Maintenance and improvement of health } & Physical health & $\begin{array}{l}\text { Promote regular exercise (9), sufficient sleep (8), screening for bone health (3), and pay } \\
\text { attention to musculoskeletal pain (7) and eye health (2). }\end{array}$ \\
\hline & Mental and spiritual health & $\begin{array}{l}\text { Promote attention to religious beliefs (3), sense of supreme being }(2) \text {, sense of thankfulness (4), } \\
\text { support for a healing environment (2), subjective well-being (1), and ability to cope with life (4) }\end{array}$ \\
\hline
\end{tabular}

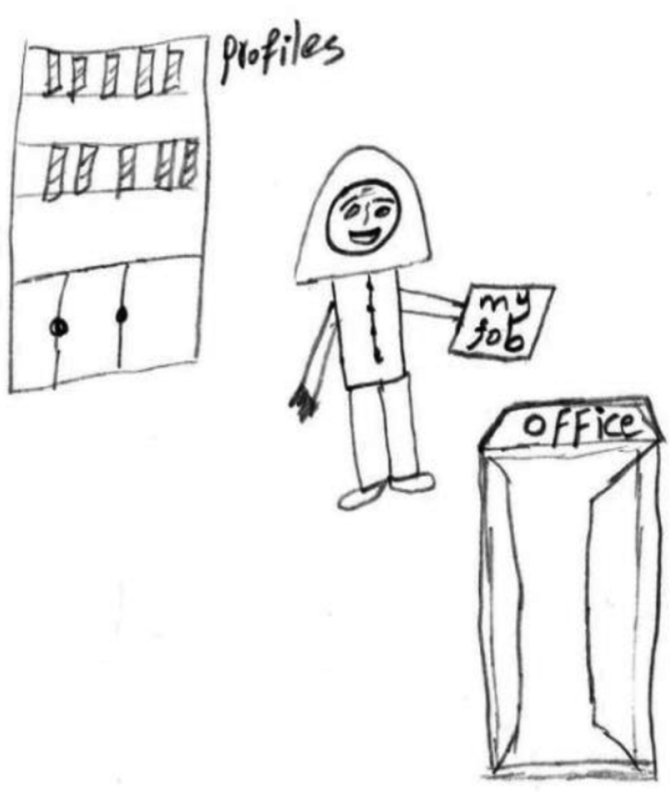

Figure 2. Student Drawing Demonstrating the Ability to Work and Feel Satisfied

\subsection{Appropriate Culture}

This category has 2 subcategories including education and moral values. The majority of the participants reported that culture played a significant role in the prevention of IA. The lack of adequate education regarding Internet usage and moral values were risk factors for the development of IA. One participant stated, "I cannot decide to stop using the Internet, I've lost all my energy and power, and no one has educated me about ways of coping with
Internet withdrawal" (25 year-old student). Another participant drew Figure 3 and stated "Internet overuse is a major problem, I don't know about Internet addiction, its signs, and negative impacts. It should be educated in university" (28 year-old student). One interviewee suggested that education should be provided from childhood. It was suggested that his/her student life would have been better if education regarding Internet usage preceded in college years. Participants mentioned that Internet usage has caused problems in social values. One student said, "When I am online, I don't pay attention to surroundings. I do not know what's going on around me. I'm in my bubble. It's probably just my way of being" (22 year-old student).
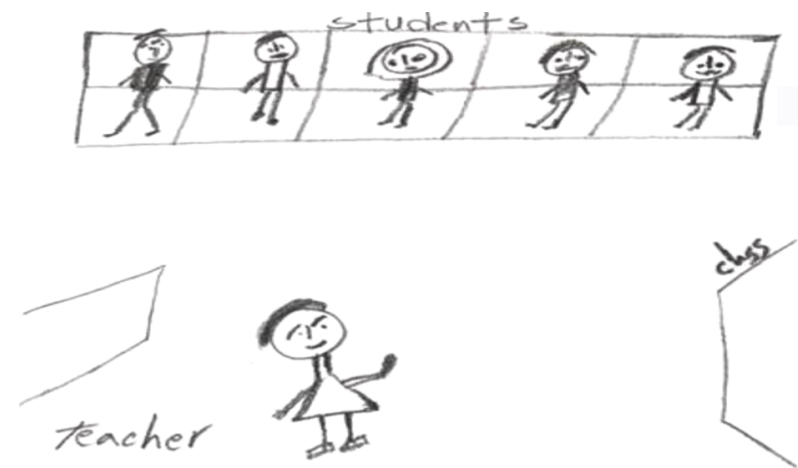

Figure 3. Need for Education to Prevent IA

\subsection{Maintenance and Improvement of Health}

This category has 2 subcategories including physical health and mental and spiritual health. Health deter- 
minants both physical and emotional were found to be strong factors affecting the development of IA. Symptoms linked to Internet overuse included dry eyes, headaches, migraines, back aches, weight gain through sedentary lifestyle, and decline in general fitness. Emotional sequela included depression and sleep issues. One student stated "before I exercised 5 - 6 times per week but now I don't have time. Before I was healthier and performed better with my workouts, but now I experience physical pain" (27 year-old student). Another reported "I felt dizzy when I sat or laid down. It was more severe when I was on the Internet. I often worried about the amount of time I spent on the Internet" (29 year-old student). Figure 4 is a drawing by a student who noted, "I spent hours on the Internet, but it causes back pain and dry eyes. I'd like to be happy and healthy" (23 year-old student). Students who identified health parameters were both a causation and result of IA. It was postulated that to decrease IA, students needed to engage in regular physical activity and attend to their emotional health needs.

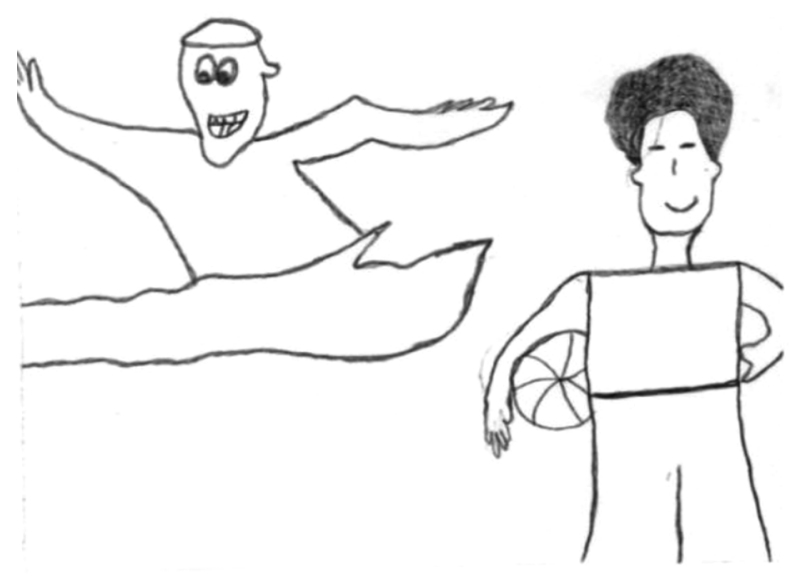

Figure 4. Health Needs to Prevent IA

\section{Discussion}

Internet usage among college students is growing at an exponential rate and the incidence of IA is concurrently on the rise $(3,26)$.

Students' needs for prevention of IA are the multidimensional. This study identified that the support of family, university, and government/administration are important protective factors. Studies have shown that lack of social support, such as family support, challenges the formation of health behaviors $(27,28)$. Family support was par- ticularly important as suggested by previous studies, due to the fact that parents can serve as emotional support, supervise children's activities, and encourage healthy behaviors (29-31). A study found that student affairs administrators can play a crucial role in preventive programs for IA by identifying students with potential academic problems (32). According to the findings of the present survey, student affairs administrators can deliver educational programs to reduce Internet overuse. These programs should help establish an appropriate culture, support social values, and promote health. They should also teach a personal competence through encouraging pro-activity and development of skills to avoid IA. As the results indicated, the government can specify separate educational space and equipment in universities and allocate a separate budget to promote health and prevent IA among college students.

The students reported that their main concern and one of their most essential needs is unemployment and their jobs are offered through the government. In Iran, most of the students are unemployed and have no access to any kinds of entertainment. They spend most of their time in dormitories or homes. Therefore, to create a mental relaxation and leisure time, students spent the majority of their time using the Internet. The government can solve students' unemployment through developing industryfocused skills programs for students, increasing student exposure to their future job in university, and promoting positive images on vocational education and apprenticeship. If officials create these programs, use of internet may decrease among students, which will result in using their spare time efficiently.

This study's results indicate that some of the respondents don't know about the effects of over-involvement with or pathological use of the Internet. A study showed that students thought that Internet overuse was not a disorder and or main problem (33). It is obvious that students need to go to counseling centers where professional help and necessary information is delivered to them. Students are reluctant to reduce hours of Internet use; they need to be skilled and trained to reduce addiction disorders. Students' affairs administration should control the expressed use of Internet. In line with our findings, a study reported that students' affairs administrators play a crucial role in designing preventive programs to reduce negative impacts of Internet use and identifying students with potential academic problems (32).

It is worth nothing that each student may have specific needs and strategies to decrease the potential dangers of Internet overuse. Students' affairs administrators and families should consider preventive educational programs to junior students. These programs should not only include culture, social values, and value of healthy body and 
mind, but it should also include increasing self-efficacy, self-control, and self-management. There is a need to team approach, which all sector such as families, communities, and the government, especial high risk groups is aware of underlining factors that cause IA.

Subjects generally described that excessive computer use cause physical and psychological problems. Our findings are consistent with other studies $(10,34)$. According to the results of the study, students should consider their own health as well as maintain and promote a healthy lifestyle with the wider communities. They should know that health is one of the most critical factor of human's lives and the basis of dynamic and creative intellectual activity. Students should consistently try to use the Internet in healthy, productive, and controlled manners. Coping with emotional and self-management is a useful skill to maintain a healthy lifestyle.

\subsection{Conclusion}

The results of the study showed that the needs of students for prevention of Internet addiction are multidimensional. They need to social support (emotional, instrumental, informational, and appraisal), strengthen individual skills to overcome barriers of health behavior, learn moral values, and apply them in their lives. Additionally, the findings stated that universities emphasize more on students' cognitive aspects as well as have a lack of attention to health aspects, especially spiritual health. Prevention programs for Internet addiction needs to promote social supports, teach personal competence, establish an appropriate culture, and prioritize good health. Results of this study showed that family support, especially emotional support, is a preventive factor for problematic internet use. Further researches can be done in the field of Internet addiction in a different group as faculty and parents.

College students are particularly vulnerable to developing dependency on the Internet (3). Understanding students' needs for preventing and managing IA can be useful for families, college education authorities, health educators, and health programs manufacturers. These findings help predict important risk factors in developing IA.

There were certain limitations to the study. Internet addiction was diagnosed through a self-reported questionnaire rather than through a detailed clinical assessment. The limited sample size and demographics of participants may limit generalizability of findings to other settings. Elearning students were excluded from the study; however, their views may differ from the participants in this study.

\section{Acknowledgments}

This work was supported by the vice chancellor for research and technology, Kurdistan University of Medical Sciences in Iran under the ethical code MUK.REC.1394. 176. We would like to expand our deepest gratitude to all students who have shared their thoughts and experiences.

\section{Footnote}

Conflict of Interests: The authors have no conflict of interest.

\section{References}

1. Chou C. Internet heavy use and addiction among Taiwanese college students: an online interview study. Cyberpsychol Behav. 2001;4(5):573-85. doi: 10.1089/109493101753235160. [PubMed: $11725650]$.

2. June KJ, Sohn SY, So AY, Yi GM, Park SH. [A study of factors that influence Internet addiction, smoking, and drinking in high school students]. Taehan Kanho Hakhoe Chi. 2007;37(6):872-82. doi: 10.4040/jkan.2007.37.6.872. [PubMed:17992059].

3. Fallahi A, Fallahi P, Nemat Shahrbabaki B, Hashemian M, Daneshvar F. Exploring factors on internet addiction in students of Sanandaj universities: A study with content analysis approach [In Persian]. Commun Health. 2016;3(1):1-10.

4. Holden C. 'Behavioral' addictions: do they exist? Science. 2001;294(5544):980-2. doi: 10.1126/science.294.5544.980. [PubMed: 11691967].

5. Yen JY, Ko CH, Yen CF, Wu HY, Yang MJ. The comorbid psychiatric symptoms of Internet addiction: attention deficit and hyperactivity disorder (ADHD), depression, social phobia, and hostility. J Adolesc Health. 2007;41(1):93-8. doi: 10.1016/j.jadohealth.2007.02.002. [PubMed: 17577539].

6. Yen JY, Ko CH, Yen CF, Chen CS, Chen CC. The association between harmful alcohol use and Internet addiction among college students: comparison of personality. Psychiatry Clin Neurosci. 2009;63(2):21824. doi: 10.1111/j.1440-1819.2009.01943.x. [PubMed: 19335391].

7. Yeap JAL. The assessment of Internet addiction among university students: some findings from a focus group. Technical Gazette. 2015;22(1):105-11. doi: 10.17559/tv-20131009152752.

8. Christakis DA, Moreno MM, Jelenchick L, Myaing MT, Zhou C. Problematic internet usage in US college students: a pilot study. BMC Med. 2011;9:77. doi: 10.1186/1741-7015-9-77. [PubMed: 21696582].

9. Grant JE, Potenza MN, Weinstein A, Gorelick DA. Introduction to behavioral addictions. Am J Drug Alcohol Abuse. 2010;36(5):233-41. doi: 10.3109/00952990.2010.491884. [PubMed: 20560821].

10. Lashgarara B, Taghavi Shahri SM, Maheri AB, Sadeghi R. Internet addiction and general health of dormitory students of tehran university of Medical Sciences [In Persian]. Sci J School Public Health Inst Public Health Res. 2012;10(1)

11. Ko CH, Yen JY, Yen CF, Chen CS, Chen CC. The association between Internet addiction and psychiatric disorder: a review of the literature. Eur Psychiatry. 2012;27(1):1-8. doi: 10.1016/j.eurpsy.2010.04.011. [PubMed: 22153731].

12. Mehrnews . 2014. Available from: http://www.asriran.com/fa/news.

13. Hashemian A, Direkvand-Moghadam A, Delpisheh A, DirekvandMoghadam A. Prevalence of internet addiction among university students in Ilam: a cross-sectional study. Int JEpidemiol Res. 2014;1(1):9-15. 
14. Durkee T, Kaess M, Carli V, Parzer P, Wasserman C, Floderus B, et al. Prevalence of pathological internet use among adolescents in Europe: demographic and social factors. Addiction. 2012;107(12):2210-22. doi: 10.1111/j.1360-0443.2012.03946.x. [PubMed: 22621402].

15. Wu CY, Lee MB, Liao SC, Chang LR. Risk Factors of Internet Addiction among Internet Users: An Online Questionnaire Survey. PLoS One. 2015;10(10):e0137506. doi: 10.1371/journal.pone.0137506. [PubMed: 26462196].

16. Cash H, Rae CD, Steel AH, Winkler A. Internet Addiction: A Brief Summary of Research and Practice. Curr Psychiatry Rev. 2012;8(4):292-8. doi: 10.2174/157340012803520513. [PubMed: 23125561].

17. Salehi M, Norozi Khalili M, Hojjat SK, Salehi M, Danesh A. Prevalence of internet addiction and associated factors among medical students from mashhad, iran in 2013. Iran Red Crescent Med J. 2014;16(5):e17256. doi: 10.5812/ircmj.17256. [PubMed: 25031856].

18. Whang LS, Lee S, Chang G. Internet over-users' psychological profiles: a behavior sampling analysis on internet addiction. Cyberpsychol Behav. 2003;6(2):143-50. doi: 10.1089/109493103321640338. [PubMed: 12804026].

19. Cao F, Su L. Internet addiction among Chinese adolescents: prevalence and psychological features. Child Care Health Dev. 2007;33(3):275-81. doi: 10.1111/j.1365-2214.2006.00715.x. [PubMed: 17439441].

20. Graneheim UH, Lundman B. Qualitative content analysis in nursing research: concepts, procedures and measures to achieve trustworthiness. Nurse Educ Today. 2004;24(2):105-12. doi: 10.1016/j.nedt.2003.10.001. [PubMed: 14769454].

21. Kvale S. InterViews-An introduction to qualitative research interviewing. Thousand Oaks: Sage; 1996.

22. Broadbent E, Ellis CJ, Gamble G, Petrie KJ. Changes in patient drawings of the heart identify slow recovery after myocardial infarction. Psychosom Med. 2006;68(6):910-3. doi: 10.1097/01.psy.0000242121.02571.10. [PubMed: 17079705].

23. Harrow A, Wells M, Humphris G, Taylor C, Williams B. "Seeing is believing, and believing is seeing": an exploration of the meaning and impact of women's mental images of their breast cancer and their potential origins. Patient Educ Couns. 2008;73(2):339-46. doi: 10.1016/j.pec.2008.07.014. [PubMed: 18722745].

24. Brown KM, Elliott SJ, Leatherdale ST, Robertson-Wilson J. Searching for rigour in the reporting of mixed methods population health research: a methodological review. Health Educ Res. 2015;30(6):811-39. doi: 10.1093/her/cyv046. [PubMed: 26491072].

25. Hadi MA, Jose Closs S. Ensuring rigour and trustworthiness of qualitative research in clinical pharmacy. Int J Clin Pharm. 2016;38(3):641-6. doi: 10.1007/s11096-015-0237-6. [PubMed: 26666909].

26. Cho $\mathrm{C}, \mathrm{Hsiao} \mathrm{M}$. Internet addiction, gratification and pleasure experience: The Taiwan college students. Comput Educ. 2010;2:680-5.

27. Cho $\mathrm{H}$, Nadow MZ. Understanding barriers to implementing quality lunch and nutrition education. J Community Health. 2004;29(5):42135. doi: 10.1023/B:JOHE.0000038656.32950.45. [PubMed: 15471423]

28. Kubo FMM, Paula J, Mialhe FL. Teachers' views about barriers in implement oral health education for school children: a qualitative study. Brazil Dental Sci. 2014;17(4):65-73. doi:10.14295/bds.2014.v17i4.1031.

29. Lin $\mathrm{CH}$, Lin SL, Wu CP. The effects of parental monitoring and leisure boredom on adolescents' Internet addiction. Adolescence. 2009;44(176):993-1004. [PubMed: 20432612].

30. Moazedian A, Taqavi SA, HosseiniAlmadani SA, Mohammadyfar MA, Sabetimani M. Parenting style and Internet addiction.J Life Sci Biomed. 2014;4(1):9-14.

31. Chen YL, Chen SH, Gau SS. ADHD and autistic traits, family function, parenting style, and social adjustment for Internet addiction among children and adolescents in Taiwan: a longitudinal study. Res Dev Disabil. 2015;39:20-31. doi:10.1016/j.ridd.2014.12.025. [PubMed: 25617844].

32. Niculović M,Živković D, Manasijević D, Štrbac N. Monitoring the effect of Internet use on students behavior case study: Technical Faculty Bor, University of Belgrade. Educ Technol Res Dev. 2012;60(3):547-59. doi: 10.1007/s11423-012-9238-5.

33. Chou C. Internet heavy use and addiction among Taiwanese college students. Cyber Psychol Behav. 2004;4(5):573-85.

34. Johnson GM. Self-esteem and use of the internet among young school-age children. Int J Psychol Stud. 2011;3(2):48-53. doi: 10.5539/ijps.v3n2p48. 